\title{
Network Niche of E-business Enterprises
}

\author{
Cequn Lou, Xiaoxi Yang \\ Information Management Department, Huazhong Normal \\ University, Wuhan, 430079, China \\ llcqd@yahoo.com.cn
}

\begin{abstract}
This paper uses the Niche concept of Ecology to analyze the role and functions of e-business in network. It discusses the network niche of ebusiness enterprises in the aspects of network function, network information resources, network technology resources and network customer resources.
\end{abstract}

\section{Introduction}

Ecological theory has been applied to human society in many fields to form new branches of ecology, such as education ecology, administration ecology and industrial ecology and so on. In the same way, we can learn from the ecological concepts and methods to explain the problems in the development of network. In 1999, the United States Department of Commerce published the report of "emerging Digital Economy". This report makes a link between ecology and network and puts forward the concept of "Internet ecology". Till now, some Chinese scholars have begun the research of network ecology. According to the statistic, Tian Zhengyu put forwarded the words of "network ecology" earliest in China. In 1998, he wrote in the paper of "network ecology": network clouds around us as the forest. Every time running the "enginery" and climbing up the network, I will inspect for the new generation of eco-system and new lives while walking through the network jungle. ${ }^{[1]}$ In this paper, "Network ecology" is only a vivid metaphor but not defined or explained exactly. In 2000, Zhang Qingfeng discussed the concept of "network ecosystem" in the paper of "The theory of ecological network". He wrote in the paper:" All the social systems which affect the development of network constitute a network development environment. When we use the perspective of link and development to analyze the interaction and mutual influence between networks and network environment, the network ecology has been formed". ${ }^{[2]}$ Many Chinese scholars research more in the aspects of network ecological systems, network ecological crisis, ecological balance of Network but less in the aspect of the theory of network niche. This paper will explore the theory of network niche in concept and its dimensions. We will also analyze the network niche of e-commerce enterprises from the overall perspective.

Please use the following format when citing this chapter:

I.ou, C., Yang, X., 2007, in IFIP International Federation for Information Processing, Volume 251, Integration and Innovation Orient to E-Socicty Volumc1, Wang, W. (Eds), (Boston: Springer), pp. 17-25. 


\section{The Concept of Network Niche}

Niche is an important ecology concept which doesn't have a unified definition currently. The definition of niche put forwarded by Whittaker in 1975 is more influential. He believed that niche means the position of time and space, functions of every species in the communities. In other words it means the relative position between a species and other species.

According to the concept of niche and the characteristics of network ecosystem, we define network niche as the specific locations of network activity participants in the network environment.

Network activity participants are individuals and social organizations which participate in the activities of computer network. They are the most active elements of network ecosystem which corresponds to concept of animals of natural ecosystems. Specifically speaking, the types of network activity participants include the government, enterprises, other organizations and individuals. Network activity participants can be classified in different ways according to different standards. For example, according to the area standard, they can be divided into political, economic, education, life, entertainment and other related participants. According to whether for the purpose of profit, they can be divided into non-profit and profit participants. In this paper, according to whether participate in the production of network resources, we classify network activity participants into network resources producers, network resources consumer and network resources transmitters. Producers produce and provide network resources as information content, network technology and other network resources. Consumers consume these network resources. Transmitters transmit network resources between different participants. The roles of network resources producers and consumers are not fixed. They will change under different conditions. For example, e-government participants are network resources producers when they issue public information and news, while they are network resources consumers when they use the software and network technology or take up the network server space.

Network eco-environment is the whole of all the other elements which impact on the network activity participants directly or indirectly. ${ }^{[3]}$ It includes hardware infrastructure, network software, network information, network policies and regulations. Hardware infrastructure is the basis of network ecosystem, which is equivalent to the soil of the natural ecosystem. The entire network resources must depend on the hardware infrastructure. Software and network-related laws and regulations are very important to the normal operation of the network ecosystems. They are equivalent to the plants of natural ecosystem to create air. Without software technology, it is impossible to present diversified network information content or to realize all the modern information services. Network information content which bases on the hardware, software, the legal foundation is equivalent to nourishment of natural ecological system. It makes network activity participants communicate and interact with each other. Leaving the network information content, networking activity participants break the relations and the network ecosystem can't exist anymore. 
In ecology, scholars study the status of life-form from the aspects of function, nutrition and space. And they put forward the dimensions of functional niche, nutrition niche, and space niche and so on. Similarly, we can analyze network activity participants from the two dimensions of network function niche and network resources niche. Network function niche reflects the role, social function, duty and authority of network activity participants. ${ }^{[4]}$

Network resources niche reflects the situation of network activity participants in production, demand, occupancy and utilization of network information, network technology and network customer resources, and other resources. Network resources niche can be subdivided into network information niche, network technology niche and network customer niche. Network information niche reflects the situation of network activity participants in production, demand, occupancy and utilization of network information. Network Technology niche reflects the situation of network activity participants in production, demand, occupancy and utilization of network technology. Network customer niche reflects the situation of network activity participants in production, demand, occupancy and utilization of network customer resources.

\section{Network Function Niche of E-commerce Enterprises}

Different network activity participants have different status and roles in the network. Network function niche of e-commerce enterprises reflects the status and function of e-commerce enterprises.

\subsection{Realizing the economic function of the network and promoting the}

\section{formation of the network economy}

Network has a variety of functions, such as the function of science, economy, education and entertainment. The economic function of network means that we can perform economic activities and create value through the network. Network performs the main economic function by exchanging economic information, producing social communication, trading all kinds of commodity, controlling economic activities. E-commerce enterprises help to accomplish this function: Firstly, e-commerce enterprises disseminate and collect economic information through the network to realize economic information exchange. Secondly, e-commerce enterprises cooperate and interact with upstream and downstream firms and clients by network to realize social production and communication functions. Thirdly, the ecommerce enterprises carry out marketing and payment online and to achieve all kinds of commodity trading. Fourthly, network promotes government to adjust and control e-commerce enterprises activities to realize function of economic activities regulated.

Broadly speaking, the network economy refers to an economic form which takes the Internet as the core, telecommunications networks, communication networks and enterprise networks, a series of networks as the foundation, the network industry as the leading power and which produces, exchanges, distributes 
and consumes commodity by network. E-commerce is an important component part of network economy. It started earliest among all the network economy activities. Ecommerce can promote the exchange of economic information and services. It also promotes the development of the network finance. For example, the development of e-business provides the new service areas and styles for the financial industry. Correspondingly, financial services content will meet the demands of e-commerce and provide relevant information support. It brings new opportunities for financial institutions, particularly in the small and medium-sized banks and emerging financial services institutions. Financial industry must adjust the services content and method to meet people's demands to let them take financial activities regardless of time and place restrictions. In this sense, it is an inevitable trend of the development of ecommerce, online banking, online payment, online personal financial management, Internet insurance agency services, online insurance quotations, online claims management, online stock trading, online investing, and online financial information services, and other electronic finance.

It shows that the development of e-business can promote the performance of network economic activities and perfect the network economy form. Although ecommerce activities are related to a wide range of activity participants, e-business enterprises play a key role in the e-commerce activities. Therefore, e-business enterprises have powerful functions in the formation and development of network economy and should not be underestimated.

\subsection{Promoting the production of information resources and the development of e-government}

Network information resources include network information content and network information technology. E-commerce enterprises can produce large amounts of business information. Activities such as internal information exchange, electronic advertising, and products development by using network, transactions between partners of supply chain, electronic financial services, electronic tax and other activities will bring a lot of information. In the information, a considerable portion is open in the network, such as the basic information of enterprises, products information, bidding information, service information, etc. The information can be used by other network activity participants. Therefore, e-commerce enterprises can promote the production of network information resource. E-commerce is a business activity in essential, and its mandate does not include the development of new network technology. However, as the development of networks and e-commerce, network technology has become the key to the success of e-commerce. Therefore, ecommerce enterprises should attach great importance on the development and application of new network technology. Some enterprises have developed network information system to meet the needs of enterprises. However, , there are often many drawbacks in this process of self-development, such as lack of staff expertise, development of the network information system not meeting the needs of corporations, development costs being too high. Under such circumstances, professional network technology companies began to flourish. These network technology companies provide support of professional network technology; develop 
new technology constantly to meet the needs of e-commerce enterprises. While ecommerce business enterprises do not have developed these new technologies, their demands on technology stimulate the development of new network technologies.

Promote the development of e-government. E-commerce enterprises promote the development of e-government through e-commerce activities in two aspects: promote government information technology and applications through e-commerce $\mathrm{B} 2 \mathrm{G}$, and fulfill the effective management and services of e-commerce through the development of e-government.

Online procurement is an important way of government procurement. It is also a natural trend of development of procurement. Online procurement saves cost for the government and improves the efficiency of the procurement center. It also achieves the principles of open, fair and competition in government procurement. Therefore, to achieve e-procurement, we must strengthen information technology to lay the foundation for the launching of e-government. The majority of business activities are conducted online after the realization of e-commerce. Business activities information will be transferred and exchanged online. It will be inefficient if the government departments use the traditional approaches to manage e-commerce activities. Egovernment can manage e-commerce enterprises easily and quickly. Industrial and commercial administrative departments can set up a special website to facilitate consumers' reporting on detrimental enterprises, inform the enterprises to correct by the way of electronic orders, electronic documents.

Online pricing departments issue electronic orders about the products pricing authority, the scope of price fluctuations, and install early warning systems. When the price is not in keeping with the provisions of the pricing department, the system will automatically feedback price information to the department of management. Commodity inspection departments will receive EDI implementation. The users can declare check by computers and the telephones. Commodity inspection departments will receive data and then input it into the computer system automatically. It accelerates the pace of the process of declaring check and also reduces input errors resulting from the duplication.

\section{Network Information Niche of E-commerce Enterprises}

Network Information Resource is an important and indispensable component in ecommerce activities. It is one part of the e-commerce activities to process and use network information resources. Network Information Resources have formed the normal operation environment in the e-commerce activities. However, network information is accessed and used by different network activities participants. Competition between network activities participants and different e-commerce enterprises exists. Therefore, e-commerce enterprises should optimize their network information resources niche from the following three aspects.

Firstly, network information niche of the e-commerce enterprises is reflected in their requirement of the content of network information. Network information resource varies in content. It includes not only scientific information, technical information, economic information, but also education information, policy and regulations information, medical information, price information, entertainment 
information, tourist information and so on. E-commerce enterprises use network to perform economic activities. Therefore, E-commerce enterprises mainly access and use network information about economic management. This information is used to analyze the situation of production, marketing and service needs to meet current customers' requirements about products. For example, enterprises can access customers' preference information to design and produce products of different functions. In the activities of e-commerce, it requires that enterprises should access feedback and demanding information at real time, predict market changes accurately, make timely adjustments and business decisions in time and improve customer satisfaction. E-commerce activities demand more credit information than others. Credit information is the evaluation about the enterprises' credit by customers and has an important impact on the e-commerce enterprises. Customers generally use two methods to get credit ratings information about e-commerce enterprises. The first way is to establish accreditation through the third party. For example, customers learn about the company's quality certificates by the state government's relevant departments. The second way is to get information through advertise in various comprehensive websites to improve enterprises' images. ${ }^{[5]}$

Secondly, the network information niche of e-commerce enterprises is reflected in the quality requirements of network information. E-commerce activities require accurate and reliable information. If e-commerce enterprises can not obtain information about national economic policies, regulations, raw materials supply of upstream enterprises, customers' demand and purchase behavior and credibility accurately by the network, it will disturb the normal development of e-commerce enterprises or lead economic loss of enterprises. However, in networks, dissemination and production of information are not stipulated. The quality of information appears uneven because of lack of standard restrictions. Therefore, when an e-commerce enterprise accesses information through networks, it should first establish reliable information access channel, in another words, it should determine to access information from which website. It is believed that to judge the accuracy and reliability of information, we should evaluate the credibility of the owners of the website. If the owners have authority, information released by their websites will be mostly high in the degree of accuracy and reliability. For instance, information on the web sites of government is all subject to strict scrutiny and almost has no mistakes. Information of this type should be regarded as the ultimate basis of ecommerce enterprises. Some personal websites information, without qualification or certification, will need to be checked stringently.

Thirdly, network information niche of the e-commerce enterprises is also reflected in the order of using network information. Network information can be shared. It won't make conflicts when e-commerce enterprises and other network activity participants use the same information at the same time. However, if other ecommerce enterprises pre-empt some network information, the value and effectiveness will be greatly weakened to the enterprises that reuse the information. In addition, network information is modified frequently. It requires e-commerce enterprises access information on the network timely. Therefore, e-commerce enterprises need to obtain information resources rapidly and seize beneficial niche of network information. 


\section{Network Technology Niche of E-commerce Enterprises}

To launch various electronic service activities online, there must be network information technology to support correspondingly. Different needs in type and properties of technology exist in different network activity participants. E-commerce enterprises will optimize their niche of network technology from the following two aspects.

Firstly, network technology niche of the e-commerce enterprises is embodied in network technology types. E-commerce activities will apply to a variety of technologies, such as network information dissemination technology which can promote and display their products, network information retrieval technology which can help customers to check the information they need, network information exchange technology to communicate with cooperation partners and customers. The most obvious difference between e-commerce and other electronic services is the use of network payment technologies. Whether for traditional transactions, or the emerging e-commerce, payment is an important part of transaction. The difference is that e-commerce payment process stresses on the means of electronically payment, which is an important component of e-commerce. ${ }^{[6]}$ Therefore, E-commerce enterprises demand more on the use of network payment technology while other participants demand less. In e-commerce activities, network security technology has the most prominent status. Because e-commerce activities involve large amounts of confidential business and financial control issues. Information about customers must be protected or it will bring huge loss to enterprises and customers. Compared with other network activities, e-commerce activities require network security more strongly. Without protection of network security technology, e-commerce activities can't be carried out. Network security technologies occupied by e-commerce enterprises include identity authentication technology, virus protection technology, data encryption technology and firewall technology. These technologies can protect e-commerce information and network security of funds transfer, and realize ecommerce functions fully. ${ }^{[7]}$

Secondly, network technology niche of the e-commerce enterprises is reflected in requirements of network technology performance. Network technology performance affects the e-commerce activities at all levels. For e-commerce activities, technologies with good performance should have the following three features: (1) Secure and stabile operations. This should be taken into account at first. Secure and stable operation of the network technology can support e-commerce activities in a normal way, solve the internal errors and prevent external intrusion. (2) Powerful functions. Network technology should be able to meet the needs of the e-commerce activities. In some cases, the use of network technology can also develop services can not be realized in real life, improve user satisfaction. (3) High level of system compatibility. Network technology should have a high degree of compatibility to avoid conflict e caused by version mismatch of equipment or software and achieve the communication with customers. 


\section{Network Customer Resource Niche of E-commerce Enterprises}

Network customers are individuals or organizations which use network to take part in various social activities. Network customers can be divided into five main types according to different purposes. The first type of purpose is to use the network information for study. These customers are mainly individuals and their activities are usually reading news, cultural knowledge and technology knowledge. They usually have better information technology and learning capacity. The second type is to entertain online. These customers are mainly individuals too. The third type is to complete various tasks, such as administrative work or data processing. These customers are generally in the form of organizations, including the government, enterprises and other organizations. The fourth type is to communicate in real-time through network. Customers of this type can be either individuals or organizations. The fifth type is to perform business and use the network for various transactions. Such customers are enterprises, organizations, or individuals.

Customers of e-commerce enterprises are mainly the fifth type, including upstream and downstream enterprises who take part in e-commerce activities online, government departments, organizations and individuals who purchase online. Judging from the current situation, B2B and B2G develop rapidly. Upstream and downstream enterprises and government departments are the main customers of ecommerce enterprises. But with the development of B2C e-commerce, A large number of families and individuals also participate in the activities of the network and make the network customers resources increasingly abundant.

However-commerce enterprises of different types and different sizes should develop, possess and use different customer resources by strengthening customer relationship management to establish, maintain and expand their network customer resources niche. E-commerce enterprises can take advanced network technology to segment markets according to their products, network market position in order to define customer troop properly. Interface of the enterprises' web site should be friendly to give customers convenient use. System pages demonstrated to customers should be accessible to communication between the system and customers allow customers involved in the product design in order to attract clients get their interests, highly satisfy personalized products and form network customer resources niche. Ecommerce enterprises should acquire individual customer information such as gender, age, occupation, loving and so on by building customer files. It is helpful for understanding customers' consumption trends. The files should be updated according to time and situation by network information technology. Enterprises can take advantage of powerful network to provide after-sales service. Enterprises can meet customers' demand by establishing of self-service platform. ${ }^{[8]}$ (Such as an online chatting room, etc.) To enable customers exchange information about products function or shortcomings, these methods can stabilize customers, maintain network customer resources niche. It is necessary to hold the old customers, stimulate potential demand, and constantly open up new markets to attract new customers in order to expand its network customer resources niche. 


\section{References}

1.Z.Y Tian. "Network Ecology", Software world, No. 2, 1998: p.130-131.

2.Q.F Zhang. "Research on Network Ecology", Information and Documentation Services, No.4, 2000: p.2-4.

3.Rafael Capurro. Towards an Information Ecology [A]. International seminar "Information and Quality"[C] 1989.[EB/OL]. [2007-3-2]. http://www.capurro.de/nordinf.htm

4.C.Q Lou. Approach on Information Niche Theories, Document, Information \& Knowledge, No. 9, 2006: p.23-27.

5.Vicki L. O'Day, Bonnie A. Nardi. Information Ecologies: Using Technology with Heart [M]. MIT Press 2002.

6.B. Hu. "On E-commerce Application Implementation Technologies". Computer knowledge and technology, No. 20, 2006: p. 63.

7. MacBride, Sean: Many Voices One World: Towards a New More Just and More Efficient World Information and Communication Order; Report of the International Commission for the Study of Communication Problems. New York, NY: UNIPUB 1980.

8.Guotai Chi. "Strategies of Customer- Relationship Management in Electronic Commerce Environment", China Soft Science, No.7, 2002: p.52-56. 